\title{
CAMA
}

Centre for Applied Macroeconomic Analysis

\section{Early 20th century American exceptionalism: Production, trade and diffusion of the automobile}

\section{CAMA Working Paper 58/2019 August 2019}

Dong Cheng

Department of Economics, Union College

\section{Mario J Crucini}

Vanderbilt University

Centre for Applied Macroeconomic Analysis, ANU

Hyunseung Oh

Department of Economics, Vanderbilt University

\section{Hakan Yilmazkuday}

Department of Economics, Florida International University

\begin{abstract}
The beginning of the twentieth century provides a unique opportunity to explore the interaction of rapid technological progress and trade barriers in shaping the worldwide diffusion of a new, highly traded good: the automobile. We scrape historical data on the quantity and value of passenger vehicles exported from the United States to other destination countries, annually from 1913 to 1940. We model the rise of US automobile from global obscurity toward a level dependent upon the extent of long-run pass-through of US prices into destination markets and destination GDP per capita. The results based on a diffusion model with CES preferences and non-unitary income elasticity shows that $62 \%$ of the gap in diffusion levels between the U.S. and the rest of the world is due to price frictions such as markups, tariffs, and trade costs, while the remaining $38 \%$ is due to income effects.
\end{abstract}




\title{
Keywords
}

Product Diffusion, Automobile, International Trade, Wedge Accounting

\author{
JEL Classification
}

F10, L62, N60, N70, O33

Address for correspondence:

(E) cama.admin@anu.edu.au

ISSN 2206-0332

The Centre for Applied Macroeconomic Analysis in the Crawford School of Public Policy has been established to build strong links between professional macroeconomists. It provides a forum for quality macroeconomic research and discussion of policy issues between academia, government and the private sector.

The Crawford School of Public Policy is the Australian National University's public policy school, serving and influencing Australia, Asia and the Pacific through advanced policy research, graduate and executive education, and policy impact. 


\title{
EARLY 20TH CENTURY AMERICAN EXCEPTIONALISM: Production, Trade and Diffusion of The Automobile*
}

\author{
Dong Cheng ${ }^{\dagger} \quad$ Mario J. Crucini ${ }^{\ddagger} \quad$ Hyunseung $\mathrm{Oh}^{\S} \quad$ Hakan Yilmazkuday ${ }^{\mathbb{I}}$
}

This version: July 8, 2019

\begin{abstract}
The beginning of the twentieth century provides a unique opportunity to explore the interaction of rapid technological progress and trade barriers in shaping the worldwide diffusion of a new, highly traded good: the automobile. We scrape historical data on the quantity and value of passenger vehicles exported from the United States to other destination countries, annually from 1913 to 1940. We model the rise of US automobile from global obscurity toward a level dependent upon the extent of long-run pass-through of US prices into destination markets and destination GDP per capita. The results based on a diffusion model with CES preferences and non-unitary income elasticity shows that $62 \%$ of the gap in diffusion levels between the U.S. and the rest of the world is due to price frictions such as markups, tariffs, and trade costs, while the remaining $38 \%$ is due to income effects.
\end{abstract}

JEL Codes: F10, L62, N60, N70, O33.

Keywords: Product Diffusion, Automobile, International Trade, Wedge Accounting.

\footnotetext{
*The authors wish to thank Bettina Aten, Diego Comin, Alan Heston, Zhu Wang and Alex Chernoff for constructive discussions, and participants at the International Comparisons Conference 2016, Midwest Macro Fall Meetings 2016, ISIR Session at the ASSA Meetings 2017, Midwest Macro Spring Meetings 2017, Canadian Economic Association Annual Conference 2017, Midwest Macro Fall Meetings 2017, QED Frontiers of Macroeconomics Workshop 2018, Midwest Macroeconomics Meetings (Fall 2018 and Spring 2019), and numerous seminars for helpful comments and advises. Any remaining errors are the joint responsibility of the authors.

${ }^{\dagger}$ Department of Economics, Union College, Email: chengd@union. edu .

${ }^{\ddagger}$ Department of Economics, Vanderbilt University, Email: mario.crucini@vanderbilt.edu .

$\S$ Department of Economics, Vanderbilt University, Email: hyunseungoh@gmail .com .

${ }^{\mathbb{I}}$ Department of Economics, Florida International University, Email: hyilmazk@fiu.edu .
} 


\section{Introduction}

This paper tells the coming-of-age-story of the automobile. Our narrative begins in 1913, one year prior to Henry Ford's introduction of full assembly-line production of the Model T chassis. This process innovation has been credited with reducing labor input requirements for chassis production from 12.5 to 1.5 (hours), a factor of more than 8 (Baldwin et al. (1987)). Shortly thereafter, the average US domestic sales price of the automobile plummeted from $\$ 1,227$ in 1913 to $\$ 659$ in 1917 (in 1940 USD). ${ }^{1}$

Figure 1 presents a more complete history of the average US domestic sales price and export unit values from 1913 to 1940 . The distinctive convex shape of the time-path of the relative price of the automobile is characteristic of new product diffusion. The relative price declines very rapidly in the first decade and stablizes by the mid-1920s. The path of the relative price over time and across countries will be the key driver of product diffusion in our model. Notice also that the average markup of export prices over domestic sales is about $20 \%$ at the start of the sample and falls to zero by the mid-1920s. As we shall show later in the paper, there is considerable cross-country variation around this average.

Based on theories of new product diffusion, one would expect automobile registrations per capita to rise quickly from a zero base toward a saturation point as the relative price settles into its long-run stationary position (which is about $\$ 550$ in real 1940 dollars in the case of the automobile). Figure 2 presents time series on automobile registrations for the United States and an aggregate of 23 other nations, for which we also have macroeconomic data. ${ }^{2} \mathrm{As}$ the relative price of automobiles falls, aggregate adoption levels rise and when relative prices stop falling, adoption rates tend to stabilize. Once the stock reaches its long-run steady state, neoclassical theory predicts that the stock of automobiles would be mainly driven by businesscycle shocks.

This diffusion story is largely born out by the evidence: a rapidly rising stock of automobiles from a low base toward a steady-state in the late $1920 \mathrm{~s}$, followed by a large negative business cycle shock, the Great Depression. The striking feature of Figure 2 is that the US automobile stock per capita is consistently 10 times higher than in the rest of the world: it reaches a peak of 200 automobiles per 1,000 population compared to less than 20 in the rest of the world. The apparent voracious appetite for automobiles in the US has been noted in the historical literature, but as far as we know, there has been no systematic documentation of international diffusion patterns over time, nor an explanation for the quantitative differences

\footnotetext{
${ }^{1}$ By US sales price, we mean the total value of domestic automobile sales divided by the quantity sold domestically. Automobile industry census of manufacturing data in 1929, 1931, 1933 and 1935 allow benchmark comparisons of the these prices to average prices of automobiles at the factory gate. All are within $9 \%$ of the annual sales price data from the US statistical abstract.

${ }^{2}$ The 23 countries in Figure 1 are: Argentina, Australia, Brazil, Canada, Chile, Colombia, Denmark, France, Greece, Italy, Japan, Mexico, New Zealand, Norway, Peru, Philippines, Portugal, Spain, Sweden, Switzerland, the United Kingdom, Uruguay, and Venezuela.
} 
across countries. Our goal is to fill this gap.

This is much more challenging than first meets the eye. Even when one abstracts from international preference differences and restricts the functional form of preferences in each country to the homothetic, constant elasticity form, the low adoption level abroad can be fully accounted for by a loci of trade friction and elasticity pairs.

For example, using a traditional trade cost friction of 15\%, the 10-fold difference between the US and foreign (aggregate) automobile adoption can be fully accounted for with an Armington elasticity of 16 . Our first result is to provide a comprehensive accounting of interwar frictions equaling 79\% (ad-valorem-equivalent) and a corresponding trade elasticity estimate of about 5. By carefully measuring the full menu of interwar frictions, we demonstrate how upward biases in the trade elasticity arise when trade frictions are under-estimated.

Our second result deconstructs the cross-country mean international price friction into its individual parts. The benchmark estimation uses three cross-sections, 1928, 1929 and 1930 and includes four frictions: an export markup at the dock, an automobile import tariff, a traditional trade cost and a Penn Effect. Together these four frictions combine to an aggregate, ad-valorem relative price friction of $79 \%$, when averaged across countries. The largest component is the Penn Effect accounting for $38 \%$ of the total friction, with the remaining three frictions (export markups, tariffs and trade costs) accounting for about 20\% each.

Our third result relates to the differences in the international price frictions across the 23 nations in our panel. The cross-sectional variance is substantial, at $28 \%$. The Penn effect accounts for almost the entire cross-sectional variance across destination markets. On the other hand, the tariff and export markups tend to cancel out. This negative covariance could be due to US producers setting relatively low prices into high tariff markets; it is also consistent with an endogenous national tariff-setting response to import penetration, or a combination of both.

\section{Related Literature}

Our work contributes to both the product diffusion literature and the voluminous empirical work that estimates the Armington trade elasticity.

Economists have measured product diffusion in two ways. One measure takes flow purchases of the good (or accumulated stocks in the case of durables) and normalizes the quantity purchased by an aggregate scale variable with the aim of finding a demand saturation point for the ratio of the two. The automobile is a good case in point. Because very few households will find it optimal to exceed one passenger vehicle per driving-age household member, a natural scale variable for the automobile is the one we use, population. Going back far enough in time, the level of adoption is zero and it rises toward a stationary quantity per capita. As with 
most product diffusions, there is a period of acceleration, followed by deceleration, in the rate of change in the adoption level. The inflection point in between is when the diffusion curve switches from convex to concave. The technical appendix reports estimates of these reducedform diffusion curves for each country in our cross-section, including the US.

An alternative measure of diffusion is intended to document how new products or technologies replace old ones. The simplest such measure takes a simple count of a new and an old vintage (or vintages) and divides each count by the total count, across all vintages currently in use. This approach has the desirable feature that it measures the market share of each vintage. However, the measure is misleading if not carefully constructed, because new products are different from old ones and some attempt must be made to convert them into a comparable flow of consumption services (or production services in the case of intermediate inputs).

A surprising feature of the existing diffusion literature is how often just two vintages of products are sufficient to characterize the relevant product space. In part, this may reflect researchers selection of products or technologies that are differentiated enough to be economically interesting. ${ }^{3}$ One prominent historical example is the replacement of the steam engine with the diesel engine in the powering of US locomotives. This process started in about 1935 and was not completed until the early 1960's. ${ }^{4}$ A more recent example is rapid access memory (RAM) which also has consisted of at most two vintages at any point in time. In sharp contrast to locomotive engines, the product cycles of RAM capacities are completed in only a few years (see, Jovanovic and MacDonald (1994)). It is worth noting that the economic impact of the move from steam to diesel is demonstrably more amenable to economic measurement than the advance of RAM in personal computers. Part of the reason is that energy can be measured on a uniform scale (e.g., joules) and, using the laws of physics, a conversion based on mass, speed and friction is possible. While the total economy-wide stock of RAM is quantifiable, measuring the end economic uses to which this RAM is obviously a daunting task.

In the context of the passenger vehicle, similar modeling challenges present themselves. Perhaps the most complete product chronology for automobiles is the volume by Baldwin et al. (1987); they summarize makes and models of automobiles spanning a century (1885 to 1987). The authors devote at least a few paragraphs to each the top 1,000 models out of approximately 4,000 that business historians have unearthed. In the interest of empirical and theoretical tractability, our focus is on the substitution margin between automobiles and an aggregate of all other goods. This approach matches up more concretely with the Armington assumption with automobiles being the US good and other goods being of foreign origin.

Following this traditional Armington-trade approach creates a point of contact with a voluminous literature that estimates trade elasticities. The recent literature has narrowed the

\footnotetext{
${ }^{3}$ For example, by focusing on electric appliances that replace mechanical ones, rather than roller blades replacing roller skates.

${ }^{4}$ Here, "started" and "completed" means dominance of one of the two technologies in powering locomotives.
} 
range of plausible values from a low of about 3 (the lower bound reported in Simonovska and Waugh (2014)) to a high of about 13 (the upper bound of estimates in Romalis (2007)). Estimates can be difficult to compare across the literature due to the different set of goods, levels of aggregation, time periods and estimation methods employed. Helpful in this regard is Anderson, Larch and Yotov (2015), who use a single panel (82 countries from 1990 to 2011 from the 8.0 version of the PWT); they report elasticity estimates spanning almost the complete range found in our survey of the literature: 4 to 11. All of our elasticity estimates fall within this range. However, the estimates are shown to fall toward the lower end of this range as we successively add observed trade frictions of different types.

Our work is also related to Comin et al. (2018) who study the role of technological progress and non-homothetic demand on international structural transformation from agriculture to manufacturers and services. They attribute a large role to income changes in structural transformation and a small role to relative price changes. Our findings show that the accounting was quite different during the interwar period, which featured a historic international tariff war.

\section{The Model}

This section develops a theoretical diffusion curve for the automobile as the solution to a consumer optimization problem. Consumers choose an optimal mix of the stock of automobiles and a composite of other goods in their aggregate consumption bundle in each year.

From this optimization problem, it is possible to derive a diffusion curve for the stock of automobiles. Using the diffusion curve for the US as the reference country (and the source of imports by foreign destinations), the US and foreign diffusion curve can be combined to backout a theoretical wedge that reconciles foreign automobile registration levels relative to the US as a function of the US domestic relative price of the automobile and foreign relative income (when preferences are not homothetic). The preference parameters governing this decision are: a substitution elasticity, an income elasticity of automobiles relative to other goods, and a taste bias. Only the latter is allowed to be country-specific. The theoretical wedge is thus the relative price difference faced by foreign consumers relative to US consumers that completely accounts for the different levels of diffusion observed in the data. In the empirical section, this theoretical wedge is deconstructed into an export markup at the border, a tariff on US automobile imports, a trade cost, a Penn Effect, and a residual.

\subsection{The Consumers Problem}

Consumers have preferences over passenger vehicles (which were refer to as automobiles hereafter) and a composite of all other goods. The appendix provides the detailed derivation of these 
optimal choices, subject to a period-by-period budget constraint. The maintained assumption is that the intra-period Euler equations holds at each date for each country.

Following an extensive literature at the intersection of macroeconomics and trade, we allow for both homothetic and non-homothetic CES preferences. We follow Comin et al. (2018) in terms of the functional form of the non-homotheticity. Specifically, the aggregate consumption index for county $j, C_{j, t}$, is implicitly defined via the constraint,

$$
\left(\Omega_{j} C_{j, t}^{\epsilon_{A}}\right)^{\frac{1}{\sigma}}\left(A_{j, t}\right)^{\frac{\sigma-1}{\sigma}}+\left(\left(1-\Omega_{j}\right) C_{j, t}^{\epsilon_{O}} \frac{1}{\sigma}\left(O_{j, t}\right)^{\frac{\sigma-1}{\sigma}}=1 .\right.
$$

The parameter, $\Omega_{j}>0$ is a taste parameter. When the CES aggregator is used in trade theory, it is referred to as the Armington aggregator to denote aggregation is taken across goods identified by their country of origin. In the two-good model referenced here we have: the US automobile, $A_{j, t}$, and a foreign bundle of all other traded goods, $O_{j, t}$. The taste parameter $\Omega_{j}$ is commonly used to generate home bias in consumption to reconcile the theory with observed trade shares. As is well-known, for every choice of the home bias parameter, there is an advalorem-equivalent trade cost the delivers the same degree of home bias in consumption, with its value determined by the elasticity of substitution. Our approach is to attribute the so-called home bias to observable trade frictions, while calibrating the preference share parameter, $\Omega$ such that it reproduces the observed interwar US automobile expenditure share. Finally, $\epsilon_{A}$ $\left(\epsilon_{O}\right)$ is the income elasticity of demand for automobiles (other goods). When these two elasticities are equal to $\sigma-1$, the preferences collapse to the standard CES, unitary income elasticity formulation.

Using the CES demand functions that arise from these preference structures, a few lines of algebra are necessary to derive a theoretical diffusion curve, which expresses the demand for automobiles, $A_{j, t}$ as a function of the sum of automobile demand and the real consumption index of all other goods. Formally, we have

$$
\omega_{j, t}=\frac{A_{j, t}}{A_{j, t}+O_{j, t}}=\frac{1}{1+\theta_{i}\left(R P_{j, t}^{A}\right)^{\sigma}}
$$

where, $R P_{j, t}^{A} \equiv P_{j, t}^{A} / P_{j, t}^{O}$ and $\theta_{i} \equiv\left(1-\Omega_{i}\right) / \Omega_{i}$. The corresponding diffusion curve for non-homothetic CES preferences is:

$$
\omega_{j, t}=\frac{A_{j, t}}{A_{j, t}+O_{j, t}}=\frac{1}{1+\theta_{i}\left(C_{j, t}^{\varepsilon_{O^{-}} \epsilon_{A}}\right)\left(R P_{j, t}^{A}\right)^{\sigma}}
$$




\subsection{The Theoretical Wedge}

In what follows it is convenient to utilize the concept of a theoretical wedge, denoted as $1+\tau_{j, t}^{*}$. By theoretical wedge, we literally mean the ad-valorem-equivalent wedge between the US domestic relative price and the foreign relative price that is necessary to exactly account for the relative adoption rates of the automobile at home and abroad, given the agents preferences and relative incomes.

To fix notation, the relative price of the automobile in country $j$, is $R P_{j, t}^{A}$, with $j=u$, denoting the comparable relative price in the US domestic market. The theoretical wedge is defined as:

$$
R P_{j, t}^{A}=\left(1+\tau_{j, t}^{*}\right) R P_{u, t}^{A} .
$$

and, given the home and foreign diffusion equations derived earlier, a few lines of algebra show that the theoretical wedge must satisfy the following equation for the homothetic CES case:

$$
1+\tau_{j, t}^{*}=\left[\frac{\left.\left(1+\theta_{i}\left(R P_{u, t}^{A}\right)^{\sigma}\right)\left(\frac{\omega_{u, t}}{\omega_{j, t}}\right)-1\right)}{\theta_{i}\left(R P_{u, t}^{A}\right)^{\sigma}}\right]^{\frac{1}{\sigma}}
$$

and the corresponding theoretical wedge for the non-homothetic CES case is:

$$
1+\tau_{j, t}^{*}=\left[\frac{\left(1+\theta_{i}\left(R P_{u, t}^{A}\right)^{\sigma}\left(C_{u, t}\right)^{\left(\epsilon_{O}-\epsilon_{A}\right)}\right)\left(\frac{\omega_{u, t}}{\omega_{j, t}}-1\right)}{\theta_{i}\left(R P_{u, t}^{A}\right)^{\sigma}\left(C_{j, t}\right)^{\left(\epsilon_{O}-\epsilon_{A}\right)}}\right]^{\frac{1}{\sigma}} .
$$

Notice that if we observe the same diffusion in the US and country $j, \omega_{u, t}=\omega_{j, t}$, this implies an absence of trade frictions, $\tau_{j, t}^{*}=0$, for homothetic preference case. When preferences are non-homothetic, we also require aggregate consumption to be equal, $C_{u, t}=C_{j, t}$.

The empirical challenge is to estimate the trade-friction and elasticity pair that best fits the equilibrium quantities observed in each country. Figure 3 provides a straightforward illustration. It shows two demand curves intersecting at the US source price and the stock of automobiles in the US. This point is set to match the US adoption of about 200 passenger vehicles per 1,000 population at a relative price of $\$ 500$ (in constant 1940 USD). The other two points reconcile the US and foreign choices (20) with two measures of the trade friction and two different elasticities. One measure of the trade friction is the one typically used in gravity estimation, the physical trade cost, which we set to $15 \%$, based on the seminal work of Hummels (2001). The second measure is the total of all empirical frictions in our interwar data, including the markups, tariffs, trade costs and the Penn Effect, which is about 79\%.

The figure illustrates the fact that underestimation of the friction leads to an overestimation of the trade elasticity. In the case of the automobile, the elasticity is biased upward from 5.4 to 34.1 , when only the gravity trade friction is included. 


\section{The Data}

The lion's share of data used in this study is a newly constructed historical panel of US automobile exports to worldwide destinations. These data were collected from annual reports filed by the Director of the Bureau of Foreign and Domestic Commerce to the Secretary of Commerce. These reports are published as an annual serial volume called the Foreign Commerce and Navigation of the United States (FCNUS). The data pulled from these reports are: the dollar value of exports and number of passenger vehicle exported to each destination country as reported in Table No. 3, Exports of Domestic Merchandise From the United States, by Articles and Countries, During the Calendar Year. The resulting unbalanced panel spans 81 nations from 1913 to 1940. Due to the empirical demands of our project most of the analysis focuses on a balanced panel of 23 countries for which macroeconomic and tariff data are also available.

The export quantity data is combined with foreign production data and a stock-flow model to estimate the stock of passenger vehicles in each destination market. These constructs are compared to international passenger vehicle registration data come from the Cross-country Historical Adoption of Technology (CHAT) database compiled by Comin and Hobijn (2009). ${ }^{5}$ Because the CHAT registration data are available for only a handful of countries during the time span of our study, the role of the CHAT is limited to cross-validation of our estimates of automobile stocks, when both measures are available.

Export prices are not recorded in the FCNUS, we compute them by dividing the value of exports to a particular destination by the number of units exported to that destination. In the trade literature, these average prices are called 'export unit values,' which is the phrase we use throughout this paper. Aside from the level of detail they provide about the international price distribution of automobiles, important for our purposes is that they are not index numbers, since our goal is to relate absolute price level differences to differences in the physical quantity purchased.

As our focus is on the role of relative prices in determining foreign automobile adoption compared to that of the US, it is crucial to understand the valuation method in these export data. As stated on page v. of FCNUS (1928): "Articles of domestic production when exported shall be valued at their actual cost or the values which they may truly bear at the time of exportation in the ports of the United States from which they are exported. In contrast, foreign exports which are goods not changed in condition and previously imported are recorded when exported in terms of their import value." Thus our export unit values are free-on-board prices.

Our approach follows the recent macroeconomics and trade literature in which Euler equations are used with a set of observable variables to back-out the composite wedge that makes

\footnotetext{
${ }^{5} \mathrm{CHAT}$ is an unbalanced panel dataset with information on the adoption of over 100 technologies in more than 150 countries since 1800 . The data is available for downloading at: http://www.nber.org/data/chat.
} 
the Euler equation hold exactly over time (and here across nations). ${ }^{6}$ The goal, then, is an empirical deconstruction of a panel of 23 nation-specific theoretical wedges over the period 1913 to 1940 into a set of observable trade frictions (or proxies for them). The frictions include: 1 ) markups at the dock, 2) tariffs, 3) trade costs (freight and insurance), and 4) retail distribution costs at the destination, the Penn effect. Due to the novelty of these data, sources and methods are discussed in considerable detail in this section. Readers interested in the elasticity estimation may skip to section 5 (the Results) without loss of continuity.

\subsection{International Stocks of Automobiles}

The first data requirement of the theory is an estimate of each nation's stock of automobiles, as this is what appears in the representative agent's utility function. There exist very few national estimates of the stocks of automobiles for the interwar period, our aim is to fill this void.

As with the construction of any capital stock, there are two methods of estimation. One entails taking a census of the outstanding stock (analogous to a population census), the alternative accumulates the flow of new purchases (investment), depreciates the pre-existing stock by a fixed proportion and sets an initial condition for the stock. Given data availability, we will rely almost exclusively on the latter method. For countries and time periods where registration data and our constructed stocks overlap, they will be compared to one another as a form of empirical cross-validation.

There are advantages and disadvantages of each estimation approach. The use of registration data is arguably the most direct method as it is the closest to a full census count of automobiles in use. And yet, the potential for significant estimation bias is real. The available registration data does not record the year the automobile was produced. This leads to an upwardly biased estimate of the effective units of transportation services embodied in the stock, because there is no account made of depreciation. Consider a newly purchased vehicle, it receives the same weight in the registration data as a vehicle that is five years old. At a depreciation rate of 0.2 , the five-year old vehicle should receive a weight of 0.4 . This problem is exacerbated in the context of a newly diffusing durable good, such as the automobile, because the average age is rising fast in the initial period of the diffusion before settling into a steady-state.

Registration data may conversely lead to downward biased estimates of true automobile stocks because of lags in the introduction of registration requirements or lax enforcement of existing ones. In the US, automobile production starts in the late 1800's, but many US states do not introduce registration as a legal requirement until the 1930s. The timing of product entry and registration was close in California, the first state to introduce registration requirements.

\footnotetext{
${ }^{6}$ This wedge accounting method was first introduced into the business cycle literature by Chari et al. (2007).
} 
It did so in 1901. While less is known about the timing of the introduction of registration requirements and their enforcement in other nations, we would expect less uniformity across nations, than across US states.

Flow data, in the form of automobile sales, are available for only a handful of nations, most of whom are also producers of automobiles. In order to achieve something close to an international census of the stock of automobiles by country, some creativity is called for. This is where the US export quantity data gains currency, provided the following three assumptions hold to a reasonable approximation.

Assumption 1: Initial condition. When registration data is lacking, the initial condition for the stock of automobiles in country $j, A_{j, 1912}$ is set to zero in 1912 (the year before the first year of our study). With the exception of the United States and a handful of advanced countries that produce automobiles, this seems to be a reasonable initial condition. Moreover, the fact that we are studying diffusion of a new product works in our favor because the impact of the estimation error of the initial stock literally 'depreciates' away.

Assumption 2: Domestic production. When no domestic production data is found, it is set to zero. For most nations of the world (there are over 80 destination markets in the full panel), this is literally true. Even in the case of the advanced industrialized countries, with a few exceptions, foreign production levels paled in comparison to the United States. In 1928, world production is estimated to be 5,273,941 of which the United States produced 4,359,759 vehicles (82.6\%), compared to 242,382 in the next largest single producer, Canada (4.6\%). ${ }^{7}$ The largest producing nations in Europe (U.K, France, Germany and Italy) account for an additional 629,400 (11.9\%) of world production. Nine other European nations produced the remaining $1 \%$. The dominance of the US industry in production is truly staggering.

Assumption 3: Non-US exports and re-exports. For the US export flow to a destination to add to the stock of automobiles consumed in that destination, it is required that the automobiles not be re-exported to a third country and also that non-US producers are not substantial sources of imports. We have no information on the extent of re-exports. Table 1 presents data for the four largest exporters of automobiles worldwide, the United States, Canada, the United Kingdom and France. Consistent with our assumptions, the US is by far the dominant source even among these industrialized countries.

Turning to the details, estimation of the automobile stock in country $j$, year $t, A_{j, t}$, using the stock-flow method is given by the following equation:

$$
A_{j, t}=(1-\delta) A_{j, t-1}+X_{j, t}+Y_{j, t}
$$

\footnotetext{
${ }^{7}$ Note that foreign subsidiaries of US companies operated in Canada and these are included in the Canadian production numbers. Thus these numbers slightly understate US production dominance.
} 
where $X_{j, t}$ represents the additions to the stock via exports to destination $j$ from the US, $Y_{j, t}$ is production in the destination, and $\delta$ is the depreciation rate (set to 0.2). The reader should keep in mind, there is no domestic production in most international destinations (i.e., $Y_{j, t}=0$ for most $j$ ).

Figure 4 presents estimates of the stock of automobiles per 1,000 population for Canada, the UK, France and Italy. The first observation to make is that while the volume of automobile production by these countries was dramatically lower than that of the United States, it was sufficient to supply most of domestic demand. This fact is evident in the enormous gulf between the black dashed lines and the red dashed lines, which represents the contribution of domestic production to the evolution of the stock. The reader is cautioned to the fact that we lack production data before 1922. Comparing the registration-based estimate to the stock-flow estimate, the correspondence is close for the U.K. and Italy, but not so for Canada and particularly, France. The tendency for overestimation of stocks using registration data in three of the four cases is consistent with the lack of depreciation of the stocks when the registration data is used.

The Philippine Islands is more typical of the international cross-section in the sense that US automobiles were the only, or by far the dominant, source of supply. Figure 5 plots the registration and the US export-based estimates of the stock using export flows. The registration data, again, consistently overstates the adoption of the automobile.

\subsection{US Prices and International frictions}

Our goal is to provide a comprehensive accounting of interwar trade frictions, as they pertain to the automobile. Toward this end, consider the following identity that relates the observed US relative price of the automobile $\left(R P_{u}^{A}\right)$ to the conjectured destination relative price $\left(R P_{j}^{A}\right)$ of the automobile in destination market $j$ :

$$
R P_{j}^{A}=\left(\frac{P_{j}^{A}}{P_{u}^{A}}\right)\left(1+s_{j}\right)\left(1+t_{j}\right)\left(\frac{S_{j} P_{u}}{P_{j}}\right) R P_{u}^{A}=\left(1+\hat{\tau}_{j}\right) R P_{u}^{A}
$$

The retail price difference between the US and destination country $j$ is attributed uniquely to four trade-related frictions. As they appear in the equation, they are:

1. A markup of the export prices over the domestic price, $\left(P_{j}^{A} / P_{u}^{A}\right)$. This markup is a standard feature of trade models that feature imperfect competition. In these settings, the producer has the ability to segment markets and engage in third-degree price discrimination (pricing-to-market).

2. A trade cost, $s_{j}$, associated with the gravity model of trade. Typically this margin is estimated by regressing bilateral trade data on distance (a proxy for the cost) and other controls. 
3. An official barrier to trade, the ad-valorem-equivalent tariff imposed by country $j$ on imports of US automobile, $t_{j}$.

4. A macroeconomic friction, the aggregate real exchange rate (i.e., the long-run deviation from PPP). This is referred to as the Penn Effect in what follows.

\subsection{Discussion of the Individual Frictions}

This subsection discusses each of the individual frictions that make up the total estimated deviation of destination prices from the US price as well as the sources and methods used to construct them.

\subsubsection{Markups}

The traditional definition of a markup in international trade is the free-on-board price to a particular destination market relative to the domestic price.

Toward this end, the export unit values in USD terms are defined as the US dollar value of exports of passenger vehicles to country $j\left(V_{j, t}^{A}\right)$ divided by the number of passenger vehicles exported to that destination, $\left(X_{j, t}^{A}\right)$ :

$$
P_{j, t}^{A}=\frac{V_{j, t}^{A}}{X_{j, t}^{A}} .
$$

To compare the entire cross-sectional distribution of these markups to US relative prices of automobiles, we divide them by the US CPI index. Figure 6 plots the median and first and third quartile of these relative prices from 1913 to 1940.

The international relative price distribution has three notable features: 1) a convex shape, with relative prices starting high, dropping rapidly and stabilizing in the last two-thirds of the sample, consistent with the earlier value-weighted version (Figure 1); 2) a non-trivial amount of dispersion in the cross-section as evident in the width of the interquartile range; and 3) the median and cross-sectional variance are unstable during World War I.

\subsubsection{Tariffs}

The US commercial policy narrative begins with campaign promises of increased tariffs by Herbert Hoover in 1928 (the business cycle peak). Originally envisioned as measures to help agriculture after the post World War I decline in the relative price of agricultural goods, the tariff revisions quickly extended to virtually all sectors of the economy (Irwin and Kroszner (1996)). Most of the available tariff history relies on the ratio of customs duties to dutiable imports as a proxy for protectionism. Aside from the obvious problem of substitution bias, there is no reason to expect the duty on automobiles to be close to this aggregate measure. 
The most comprehensive analysis of microeconomic tariff distortions in the United States is Bond et al. (2013), which covers more than 5,000 tariff-lines. The mean ad-valorem-equivalent tariff rose from $32 \%$ to $46 \%$ after the passage of Hawley-Smoot in June 1930. The tariff levels ranged from $0 \%$ to over $200 \%$. Specific to automobiles, US import duties on automobiles were actually cut from $25 \%$ to $10 \%$ (though import duties on automobile parts remained constant at $25 \%)$.

In the 1920s, many countries had much higher duties on automobiles than did the United States and raised them, partly in retaliation to higher US duties on their exports to the United States. We have two cross-sections of automobile tariffs spanning 23 countries. The median ad-valorem-equivalent tariff rate across these countries increased from $17 \%$ to $34 \%$, from 1920 to 1921. Averaging across the two years, the cross-country average tariff was $25 \%$. Table 2 reports country level ad-valorem-equivalent tariff rates for all 23 countries in 1920, 1921 and the average of these two years. The calibration results below use the average tariff across 1920 and 1921, the cross-sections for which we also have GDP data.

\subsubsection{Trade Costs}

One of the most robust empirical relationships in the trade literature is the fact the bilateral trade between nations is declining in the distance between them. This 'gravity' model of trade also has found that the volume of trade between two nations is roughly proportional to the product of their aggregate output.

Following the empirical trade-gravity model, we regress the logarithm of the ratio $\omega_{j, t} / \omega_{u, t}$ (the inverse of the ratio of our Euler equation) on a constant and the logarithm of distance (between capital cities):

$$
z_{j, t}=\ln \omega_{j, t}-\ln \omega_{u, t}=\underset{(0.73)}{0.52} \underset{(0.08)}{0.44 \ln }\left(d_{j}\right)+\epsilon_{j, t}
$$

The coefficient on distance is -0.44 , is remarkably close to the average reported in the meta analysis of the gravity literature (Disdier and Head (2008)).

As is well-known from the theoretical gravity literature, the reduced form coefficient on distance is the product of a substitution elasticity and the slope coefficient linking distance to trade costs (typically: $\ln (1+\tau)=\beta \ln \left(d_{j}\right)$ ). In principle, it is possible to disentangle these two margins, by substituting the predicted values of the gravity equation for quantities into the Euler equation with the US domestic relative price set to unity, to generate a cross-section of implied trade cost frictions. As if often the case with this method of indirect inference, the absolute size of the friction is implausibly large: over 50\% ad-valorem-equivalent for a plausible trade elasticity. Rather than rely on this dubious estimate, we use direct estimates of automobile freight costs Hummels (2001). While his work uses contemporary data, the advalorem-equivalent levels are more plausible, in the neighborhood of $15 \%$. 


\subsubsection{The Penn Effect}

The Penn Effect is the robust positive correlation between aggregate price levels and income level across countries. To understand its role in studying the demand for the automobile, suppose the LOP held exactly for automobiles. Since prices are, in general, higher in rich countries, the automobile would be relatively inexpensive in high income countries. In practice, how much less expensive they will be depends on the difference between the share of retail distribution costs for the automobile relative to the other goods in the consumption basket. While it is difficult to determine these values for the interwar period, contemporary estimates of the distribution share for the aggregate consumption basket are about 0.55 , while those for the automobile are about 0.25. Therefore, the relative Penn Effect is 0.25-0.55=-0.30. Put differently, an automobile that satisfies the Law-of-One-Price across destination based upon the price at the destination port will be $3 \%$ less expensive in relative terms across countries that have a $10 \%$ real income differential. Due to possible structural changes as the retail sector grows in economic importance latter in US history, we include a sensitivity analysis for the Penn effect.

\section{Results}

The section reports the results of estimating substitution and income elasticities. We also conduct variance decompositions of the theoretical wedge into its observable empirical trade frictions: trade costs, tariffs, export markups and the Penn Effect.

From this point forward, we suppress the time subscripts and mention the time dimension only when it is used in the estimation.

\subsection{Elasticity Estimation}

We begin by noting variables that are pre-set, including normalizations. The automobile share of aggregate consumption expenditure is set to $\Omega_{A, j}=0.03$ based on the extensive study of durable goods during the interwar period by Onley (1985). The US CPI is used to proxy for the price index of the non-automobile basket, $P_{u, t}^{O}{ }^{8}$ The relative price of the automobile in the US, $R P_{u, t}^{A}$, is set to 1 in 1921. Finally, real PPP-adjusted income in each country is normalized to the level of real PPP-adjusted income in the US in 1921. In words, US real income is 1 in 1921 and other country's income is measured relative to this base.

The elasticity of substitution and differential income elasticity (for the non-homothetic preference case) are estimated by minimizing the distance between the theoretical wedge and

\footnotetext{
${ }^{8}$ Because of the small expenditure share of automobiles, replacing the CPI index with a constructed nonautomobile price index yields the same quantitative results.
} 
the total measured empirical friction:

$$
\left(1+\tau_{j, t}^{*}\right)=\left(\frac{\left(\left(1+\left(R P_{u, t}^{A}\right)^{\sigma}\right)\left(\frac{\widetilde{\omega}_{u, t}}{\widetilde{\omega}_{j, t}}\right)-1\right)}{\left(R P_{u, t}^{A}\right)^{\sigma}}\right)^{\frac{1}{\sigma}}=\left(\frac{P_{j, t}^{A}}{P_{u, t}^{A}}\right)\left(1+s_{j}\right)\left(1+t_{j}\right)\left(\frac{S_{j, t} P_{u, t}}{P_{j, t}}\right)\left(1+\epsilon_{j}\right)
$$

At this point, the reader may wish to refer back to the empirical section to understand the composition structure of the aggregate empirical friction. Notice that there are two timevarying components and two time-invariant components. The time varying empirical frictions are the export unit values relative to US domestic prices and the aggregate real exchange rate. The time-invariant empirical frictions are the traditional trade cost and the foreign tariff on US automobile imports.

\subsection{Cross-sectional versus Time Series Variation}

One key advantage of our panel constructs is that the price and quantity data are not index numbers. As such, there is meaningful variation both in the cross-sectional dimension and the time series dimension. To fully understand the sources of microeconomic variation in our panel, we follow the variance decomposition method employed by Crucini and Telmer (2019).

$$
\begin{aligned}
\operatorname{var}\left(\ln \left(1+\tau_{j, t}^{*}\right)\right) & =\operatorname{var}_{j}\left[E_{t}\left(\ln \left(1+\tau_{j, t}^{*}\right)\right)\right]+E_{j}\left[\operatorname{var}_{t}\left(\ln \left(1+\tau_{j, t}^{*}\right)\right)\right] \\
V & =C+T
\end{aligned}
$$

In words: the total variance of the logarithm of the theoretical wedge in the panel $(V)$ may be decomposed into the cross-sectional variance (across nations) of the conditional mean (the time averaged wedges), denoted by $C$, and the mean (average across countries) of the conditional variance (time series variance by country) relative to these long-run means, denoted by $T$.

We begin with the variance decomposition of the quantity ratios, since the variance of the theoretical wedges will depend upon the elasticity of substitution. The first row of Table 3 reports this two-way analysis of variance for the diffusion ratios (foreign relative to the US). The total variation in relative automobile diffusion per capita is substantial at $8.55 \%$. Of this total, $7.18 \%$ is cross-sectional variation - variation in the time-averaged levels of diffusion. The remaining $4.64 \%$ is time series variation around these long-run, county-specific, time averages.

The lower panel repeats the exercise for the theoretical wedges using calibrations of the elasticity of substitution of 6 and 9. The theoretical Euler equation predicts that as the elasticity of substitution declines, the variation of the relative price for a given observed variation in relative quantities, must rise. This is manifest in the increase in the total variance of the theoretical wedge from $14.2 \%$ to $21.1 \%$ as the elasticity of substitution is lowered from 9 to 6. Notice that while the absolute level of the variance rises, its composition remains highly skewed in favor of the cross-sectional component. The ratio of cross-sectional to total vari- 
ance is about three-quarters in both cases. Note, also, that this ratio is similar to that of the quantity ratios reported in the upper part of the table.

\subsection{Elasticity Estimates}

Table 4 reports a comprehensive set of non-linear least squares estimation results. The computation method we follow is the Levenberg-Marquardt nonlinear least squares algorithm that iterates parameters of interest to minimize the sum of squared deviations.

There are 32 estimated substitution elasticities. The columns labelled time averaged refer to estimation results where the data have been averaged over the sample periods noted. The columns labelled pooled cross-section use the full panel data, again for the sample periods noted. Notice that the elasticity estimates are virtually identical across these cases. This finding is entirely consistent with the variance decomposition method of the previous section. Recall that $75 \%$ of the variation in the relative diffusion level is cross-sectional, not time series. An implication of this is that the elasticity estimates are not much affected by averaging away the latter source of variation. A more subtle implication of this is that the results are also insensitivity to the sample period of estimation. This can be seen by comparing estimates across rows in a particular column and panel. For example, the substitution elasticity when all observed frictions are included is 5.385, for the 1928-1930 period and 5.621, for the 19131940 period.

Given that most of the transitional diffusion dynamics have been worked off by the 19281930 period, these are the results we consider most reliable given our use of a static Euler equation. But, for the purpose of substitution elasticity comparisons, it really does not matter much. What matters a great deal, is the measurement of the empirical frictions.

The panels are organized so that results with the full set of trade frictions appear in Panel A and the single, export markup friction, results appear in Panel D. In between, the Penn Effect is set to an intermediate level (i.e., less strongly correlated with destination income than in the benchmark) or eliminated entirely. As predicted by the theory with CES homothetic preferences, the substitution elasticity increases monotonically as the empirical frictions are removed, one-by-one. Put differently, the substitution elasticity is biased upward to the extent the empirical frictions are underestimated (or ignored). These biases are substantial. Consider the time-averaged case using the 1929-1930 sample. The elasticity of substitution is 5.385 with all three frictions, it rising to 9.142 when the Penn Effect is removed and further to 20.4 when all frictions except the export markups are excluded. The non-homothetic case tells a similar story. Without the Penn Effect, the elasticity of substitution is 7.3 and it rises to 17.2 when the only trade friction is the export markup friction.

Notice that the Penn Effect also has consequences for the estimated differential income elasticity across automobiles and other goods. Recall, the Penn Effect works to make prices 
relatively low in high income destinations (high real exchange rate or price level countries). Consequently, the Penn Effect works in the same direction as the differential income elasticity for automobiles. As the Penn effect is weakened, or eliminated, the estimated income differential effect strengthens.

The bottom line of the estimation results is that the elasticity of substitution is in the range of 5 to 9 , with our preferred estimates closer to the bottom of this range. Preferred, being either the homothetic case with a full set of frictions, or the non-homothetic case with at least the trade cost and tariff frictions included. These elasticities are in the range of those found in the contemporary literature. However, the size and composition of the trade frictions may be quite different. To explore these issues, we turn to a decomposition of the theoretical wedge into individual empirical frictions.

\section{Variance Decomposition of Wedges into Frictions}

In what follows, our focus is on the time averaged data for 1928-1930; effectively cross-sectional variance at about the time countries had reached a stationary, pre-Depression adoption level.

\subsection{Variance Decomposition of the Trade Frictions}

Table 5 reports two benchmark cases, the case will all four empirical frictions (each enumerated in a separate column) and a case that excludes the Penn Effect. The first section of each panel is the cross-country average friction, so a single value. The average foreign friction is 0.79 in the data, when we include all four components of the frictions, effectively a $79 \%$ advalorem-equivalent friction. The implied theoretical wedge necessary to match the quantity data is $73 \%$, so our cumulative empirical friction is $6 \%$ higher than needed to account for the mean difference of adoption between the average foreign country and the US. The second row normalizes all columns by the theoretical wedge, indicating the empirical friction is $8.1 \%$ higher than the theoretical friction implied by the quantity data.

The third row normalizes each empirical trade friction to their sum, to give a sense of their relative contribution. The largest individual component is the Penn Effect, which accounts for almost $40 \%$ of the total. The remaining three empirical frictions, the export markup, tariff and trade cost each contribute about $20 \%$.

Panel B omits the Penn Effect. In this case the aggregate empirical friction is only $49 \%$ since the Penn Effect was 30\% in Panel A. Keep in mind that the estimated elasticity increases to compensate, from 5.385, in Panel A, to 9.142, in Panel B. The upshot is that the theoretical wedge and empirical frictions are still comparable in magnitude, but both are smaller in absolute value. The contributions of the export markup, tariff and trade cost rise in proportion, but - of course - remain the same relative order of magnitude to one another as was the case 
with all four trade frictions included. Now, these three trade frictions each contribute in the neighborhood of one-third to the total variance.

The lower two panels explore the variance of the theoretical and empirical frictions across countries. These variance decompositions are computed using the covariance method:

$$
\operatorname{var}_{j}\left(\ln \left(1+\tau_{j}^{*}\right)\right)=\sum_{i} \operatorname{cov}_{j}\left(\ln \left(1+\tau_{j}^{*}\right), \ln \left(1+\tau_{i j}\right)\right)
$$

where $\tau_{j}^{*}$ is the theoretical wedge in country $j$ and $t_{i j}$ is the ad-valorem-equivalent friction of type $i$ in country $j$.

Like the mean, the variance of the theoretical wedge across countries is higher when the elasticity of substitution is lower, 0.262 in Panel C compared to 0.154 in Panel D. The model with all empirical frictions accounts for 53.5\% of the cross-sectional variation in the theoretical wedges (and, by implication, quantities). However, when the Penn Effect is omitted that fraction drops to just $2 \%$.

The dramatic decline in the ability of the model to account for cross-country differences in the theoretical wedge when the Penn effect is omitted, reflects two features of the empirical frictions.

First, the trade cost is set to a common value across countries. While this is a calibration decision, recall the distance between each nation and the US is about equal with the exception of a few bilateral pairs. So, the fact of the matter is that distance is not going to account for the cross-sectional variance of the theoretical wedge even though it contributes significantly to explaining the mean theoretical wedge.

Second, the tariff is negatively correlated with the aggregate theoretical wedge. This likely reflects the joint endogeneity of export unit values and tariff setting. As the price of US automobiles falls and this gets reflected in export unit values, countries may be raising their tariffs to offset the pass-through of automobile prices into their respective domestic markets. Alternatively, Ford may be charging lower markups into destination markets with higher tariffs to establish a market presence in those destinations. The upshot is that these two margins tend to cancel out in the cross-section, leaving the Penn Effect to capture the lion's share of the cross-sectional variation.

We do not report analogous decompositions of wedges for the case of non-homothetic preferences because the numbers are very similar. Instead, we turn to decompositions of the diffusion levels themselves, in terms of the predicted contribution of prices (substitution effects) and income (income effects). 


\subsection{Variance Decomposition of Relative Automobile Adoption Rates}

Table 6 investigates the model's implications for variation in the relative diffusion rates under non-homothetic CES preferences using the same frictions and data as used in Table 5.

Beginning with the mean, the average ratio of foreign to US diffusion per capita is 0.055 . Recall, that this means US consumers have about 18 (1/0.055) registered passenger vehicles per 1,000 population for every 1 vehicle registered per 1,000 population in foreign countries. The substitution (or price) effect accounts for $62 \%$ of this difference and the relative income effect accounts for the remaining 38\%, when all four frictions are included. When the Penn Effect is ignored (see Panel B), the decomposition is virtually unchanged.

Turning to the cross-country differences in diffusion (relative to the US), in Panels C and $\mathrm{D}$, the standard deviation is about $10 \%$. About $80 \%$ of this is accounted for by prices and about $20 \%$ by income. Again, these results are not materially affected by the inclusion of a Penn Effect.

\section{Conclusion}

This paper has investigated the diffusion of automobiles in the U.S. versus the rest of the world between 1913-1940. Since virtually all automobiles were produced in the U.S. (and exported to the rest of the world) during this period, the U.S. exports and the corresponding source prices, together with data on various trade frictions, have been investigated.

The results based on a diffusion model with CES preferences and non-unitary income elasticities have shown that about $62 \%$ of the gap in diffusion levels between the U.S. and the rest of the world is due to price frictions such as markups, tariffs, and trade costs (with almost equal contributions of about $20 \%$ ), while the remaining $38 \%$ is due to income effects. 


\section{References}

[1] Anderson, James E., Mario Larch, and Yoto V. Yotov. 2015. "Growth and Trade with Frictions: A Structural Estimation Framework," NBER Working Papers, No. 21377.

[2] Baldwin, Nick, G. N. Georgano, Michael Sedgwick, and Brian Laban. 1987. The World Guide to Automobile Manufacturers. Facts on File Publications.

[3] Bresnahan, Timothy F. and Daniel M.G. Raff. 1991. "Intra-Industry Heterogeneity and the Great Depression: The American Motor Vehicles Industry, 1929-1935,” Journal of Economic History, 51: 317-331.

[4] Chari, V.V., Patrick J. Kehoe and Ellen R. McGrattan. 2007. "Business Cycle Accounting " Econometrica, 75(3):781-836.

[5] Bond, Eric W., Mario J. Crucini, Tristan Potter, and Joel Rodrigue. 2013. "Misallocation and Productivity Effects of the Smoot-Hawley Tariff," Review of Economic Dynamics, 16: 120-134.

[6] Comin, Diego A. and Bart Hobijn. 2009. “The CHAT Dataset,” NBER Working Paper, No. 15319.

[7] Comin, Diego, Danial Lashkari and Marti Mestieri. 2018. "Structural Change with Long-run Income and Price Effects," mimeo.

[8] Crucini, Mario J. and Christopher I. Telmer. 2019. "Microeconomics Sources of Real Exchange Rate Variation,” National Bureau of Economic Research Working Paper No. 17978.

[9] Disdier, Anne-Célia and Keith Head. 2008. "The Puzzling Persistence of the Distance Effect on Bilateral Trade," Review of Economics and Statistics, 90(1): 37-48.

[10] Hummels, David. 2001. "Toward a Geography of Trade Costs," mimeo, Purdue University.

[11] Irwin, Douglas A. and Randall S. Kroszner. 1996. "Log-rolling and Economic Interests in the Passage of the Smoot-Hawley Tariff," Carnegie-Rochester Conference Series on Public Policy, 45: 173-200.

[12] Jovanovic Boyan and Glenn M. MacDonald. 1994. "The Life Cycle of a Competitive Industry," Journal of Political Economy, 102(2): 322-347.

[13] Lee, Changkeun. 2016. "Was the Great Depression Cleansing? Evidence from the American Automobile Industry, 1929-1935,” mimeo, University of Michigan.

[14] Onley, Martha. 1985. "Advertising, Consumer Credit, and the "Consumer Durables Revolution" of the 1920s," Ph.D. Dissertation, University of California, Berkeley.

[15] Romalis, John. 2007. "NAFTA's and CUSFTA's Impact on International Trade," Review of Economics and Statistics, 89(3): 416-435.

[16] Simonovska, Ina and Michael E. Waugh. 2014. "The Elasticity of Trade: Estimates and Evidence," Journal of International Economics, 92(1): 34-50. 
[17] Vickers, Chris and Nicolas L. Ziebarth (2017). "The Census of Manufactures: An Overview," Work in Progress, Auburn University. 
Table 1. Bilateral Trade in Automobiles (1923-1928)

\begin{tabular}{|c|c|c|c|c|c|c|}
\hline \multirow{3}{*}{$\begin{array}{l}\text { Importer } \\
\text { Country }\end{array}$} & \multirow{3}{*}{$\begin{array}{l}\text { United } \\
\text { States }\end{array}$} & \multicolumn{4}{|c|}{ Non-US exporters } & \multirow[b]{3}{*}{ Total } \\
\hline & & \multirow[b]{2}{*}{ Canada } & \multicolumn{2}{|c|}{ United } & \multirow[b]{2}{*}{ Other } & \\
\hline & & & Kingdom & France & & \\
\hline Argentina & 87.0 & 11.5 & 0.2 & 1.3 & 0.0 & 100 \\
\hline Brazil & 92.0 & 6.9 & 0.1 & 0.9 & 0.0 & 100 \\
\hline Canada & 93.4 & 4.9 & 1.7 & 0.0 & 0.0 & 100 \\
\hline Columbia & 86.7 & 13.1 & 0.0 & 0.0 & 0.2 & 100 \\
\hline France & 85.7 & 2.2 & 12.0 & 0.0 & 0.0 & 100 \\
\hline Greece & 100 & 0.0 & 0.0 & 0.0 & 0.0 & 100 \\
\hline Italy & 82.8 & 0.0 & 0.6 & 16.6 & 0.0 & 100 \\
\hline Norway & 81.8 & 12.2 & 2.5 & 3.6 & 0.0 & 100 \\
\hline Peru & 100 & 0.0 & 0.0 & 0.0 & 0.0 & 100 \\
\hline Philippine Islands & 100 & 0.0 & 0.0 & 0.0 & 0.0 & 100 \\
\hline Portugal & 90.7 & 0.0 & 9.3 & 0.0 & 0.0 & 100 \\
\hline Sweden & 93.3 & 6.5 & 0.2 & 0.0 & 0.0 & 100 \\
\hline Uruguay & 90.2 & 9.8 & 0.0 & 0.0 & 0.0 & 100 \\
\hline Venezuela & 85.6 & 13.4 & 0.0 & 0.0 & 1.0 & 100 \\
\hline Average & 90.7 & 5.8 & 1.9 & 1.6 & 0.0 & 100 \\
\hline Australia & 75.8 & 21.7 & 2.5 & 0.0 & 0.1 & 100 \\
\hline Japan & 74.8 & 14.7 & 2.9 & 7.6 & 0.0 & 100 \\
\hline New Zealand & 46.5 & 43.6 & 9.9 & 0.0 & 0.0 & 100 \\
\hline Spain & 54.1 & 0.9 & 1.1 & 43.9 & 0.0 & 100 \\
\hline Switzerland & 31.8 & 0.0 & 0.8 & 67.4 & 0.0 & 100 \\
\hline United Kingdom & 44.2 & 29.2 & 0.0 & 26.6 & 0.0 & 100 \\
\hline Average & 54.5 & 18.4 & 2.9 & 24.2 & 0.0 & 100 \\
\hline
\end{tabular}

Notes. The upper panel of the table list countries for which the United States accounts for $80 \%$ of more of their automobile imports. The lower panel are countries that source more significantly from Canada, France or the United Kingdom. See the data appendix for details of original data sources. 
Table 2. Tariffs on Passenger Automobiles

\begin{tabular}{lccc}
\hline \hline Country & Average & 1920 & 1921 \\
\hline Argentina & Panel A: Constant Tariffs & \\
Canada & 0.320 & 0.320 & 0.320 \\
Chile & 0.388 & 0.425 & 0.350 \\
Colombia & 0.239 & 0.238 & 0.239 \\
France & 0.012 & 0.012 & 0.011 \\
New Zealand & 0.450 & 0.450 & 0.450 \\
Norway & 0.200 & 0.200 & 0.200 \\
Philippine Islands & 0.150 & 0.120 & 0.180 \\
Sweden & 0.000 & 0.000 & 0.000 \\
Switzerland & 0.150 & 0.150 & 0.150 \\
United Kingdom & 0.084 & 0.084 & 0.084 \\
Uruguay & 0.333 & 0.333 & 0.333 \\
Venezuela & 0.265 & 0.240 & 0.290 \\
\hline Mean & 0.017 & 0.017 & 0.016 \\
Standard Deviation & $\mathbf{0 . 1 4 9}$ & $\mathbf{0 . 1 9 9}$ & $\mathbf{0 . 2 0 2}$ \\
\hline & Panel B: Escalating Tariffs & $\mathbf{0 . 1 5 1}$ \\
\hline Australia & 0.322 & 0.100 & 0.543 \\
Brazil & 0.207 & 0.158 & 0.257 \\
Denmark & 0.076 & 0.029 & 0.123 \\
Greece & 0.120 & 0.090 & 0.150 \\
Italy & 0.373 & 0.154 & 0.591 \\
Japan & 0.425 & 0.350 & 0.500 \\
Mexico & 0.179 & 0.000 & 0.358 \\
Peru & 0.246 & 0.110 & 0.382 \\
Portugal & 0.768 & 0.196 & 1.339 \\
Spain & 0.470 & 0.077 & 0.863 \\
\hline Standard Deviation & $\mathbf{0 . 1 2 6}$ & $\mathbf{0 . 5 1 1}$ \\
\hline
\end{tabular}


Table 3. Variance Decomposition of Diffusion and Theoretical Wedge (percentage)

\begin{tabular}{lcccc}
\hline \hline & $\begin{array}{c}\text { Cross } \\
\text { Section }\end{array}$ & $\begin{array}{l}\text { Time } \\
\text { Series }\end{array}$ & Total & $\frac{\text { Cross-section }}{\text { Total }}$ \\
\hline Relative Diffusion & 7.18 & 4.64 & 8.55 & 70.6 \\
& & & & \\
Theoretical Wedge & & & & \\
$\sigma=9$ & 12.2 & 7.3 & 14.2 & 73.9 \\
$\sigma=6$ & 18.3 & 10.5 & 21.1 & 75.1 \\
\hline \hline
\end{tabular}

Notes. The theoretical wedge is backed out using: $\left(1+\tau_{j, t}^{*}\right)=\left[\frac{\left(\left(1+\left(R P_{u, t}^{A}\right)^{\sigma}\right)\left(\frac{\omega_{u, t}}{\omega_{j, t}}\right)-1\right)}{\left(R P_{u, t}^{A}\right)^{\sigma}}\right]^{\frac{1}{\sigma}}$, where $\omega_{u, t}$ and $\omega_{j, t}$ are diffusion ratios and measured using estimated stocks per capita for the foreign countries (foreign production combined with US export flows) and registration per 1,000 population for the US case. 
Table 4. Substitution and Income Elasticity Estimates.

\begin{tabular}{|c|c|c|c|c|c|c|}
\hline \multirow[b]{4}{*}{ Sample } & \multirow{2}{*}{\multicolumn{2}{|c|}{$\begin{array}{c}\text { Homothetic CES } \\
\text { Substitution Elasticity }\end{array}$}} & \multicolumn{4}{|c|}{ Non-homothetic CES } \\
\hline & & & \multicolumn{2}{|c|}{ Substitution Elasticity } & \multicolumn{2}{|c|}{ Relative Income Elasticity } \\
\hline & Time & Pooled & Time & Pooled & Time & Pooled \\
\hline & Averaged & Cross-sections & Averaged & Cross-sections & Averaged & Cross-sections \\
\hline \multicolumn{7}{|c|}{ Panel A: NLS with All Four Empirical Frictions } \\
\hline \multirow[t]{2}{*}{$1928-1930$} & 5.385 & 5.387 & 7.644 & 7.622 & 1.579 & 1.563 \\
\hline & $(0.355)$ & $(0.222)$ & $(1.916)$ & $(1.185)$ & $(1.21)$ & $(0.748)$ \\
\hline \multirow[t]{3}{*}{$1913-1940$} & 5.621 & 6.124 & 7.269 & 8.257 & 1.177 & 1.573 \\
\hline & $(0.317)$ & $(0.101)$ & $(1.388)$ & $(0.429)$ & $(0.892)$ & $(0.275)$ \\
\hline & & el B: NLS with & Ir Empirical & ictions (Weak Pe & Effect) & \\
\hline \multirow[t]{2}{*}{$1928-1930$} & 6.805 & 6.81 & 7.457 & 7.447 & 0.365 & 0.357 \\
\hline & $(0.579)$ & $(0.359)$ & $(1.932)$ & $(1.17)$ & $(0.993)$ & $(0.601)$ \\
\hline \multirow[t]{3}{*}{$1913-1940$} & 7.092 & 7.637 & 7.256 & 8.257 & 0.094 & 0.371 \\
\hline & $(0.528)$ & $(0.158)$ & $(1.477)$ & $(0.431)$ & $(0.780)$ & $(0.228)$ \\
\hline & & nel C: NLS with & ree Empiric & rictions (No Per & Effect) & \\
\hline \multirow[t]{2}{*}{ 1928-1930 } & 9.142 & 9.157 & 7.307 & 7.307 & -0.777 & -0.782 \\
\hline & (1.158) & $(0.707)$ & (1.962) & (1.171) & $(0.799)$ & $(0.476)$ \\
\hline \multirow[t]{3}{*}{$1913-1940$} & 9.464 & 10.04 & 7.254 & 8.286 & -0.969 & -0.810 \\
\hline & $(1.078)$ & $(0.293)$ & $(1.566)$ & $(0.437)$ & $(0.668)$ & $(0.190)$ \\
\hline & & Panel D: & S with Onl & xport Markups & & \\
\hline \multirow[t]{2}{*}{ 1928-1930 } & 20.402 & 20.749 & 17.225 & 17.56 & -0.595 & -0.571 \\
\hline & $(4.016)$ & $(2.727)$ & $(7.448)$ & $(4.945)$ & $(1.308)$ & $(0.848)$ \\
\hline \multirow[t]{2}{*}{ 1913-1940 } & 21.073 & 21.943 & 16.229 & 17.623 & -0.946 & -0.891 \\
\hline & $(2.772)$ & $(1.15)$ & $(4.037)$ & $(1.624)$ & $(0.747)$ & $(0.311)$ \\
\hline
\end{tabular}

Notes. Standard errors are in parentheses. 
Table 5. Decomposition of Frictions

(Homothetic CES Preferences, Time Averaged Data, 1928-1930)

\begin{tabular}{lccccccc}
\hline \hline & $\begin{array}{c}\text { Theoretical } \\
\text { Wedge }\end{array}$ & $\begin{array}{c}\text { Empirical } \\
\text { Friction }\end{array}$ & $\begin{array}{c}\text { Export } \\
\text { Markup }\end{array}$ & $\begin{array}{c}\text { Ad-Valorem } \\
\text { Tariff }\end{array}$ & $\begin{array}{c}\text { Penn } \\
\text { Effect }\end{array}$ & $\begin{array}{c}\text { Trade } \\
\text { Cost }\end{array}$ & Residual \\
\hline \multicolumn{7}{c}{$\begin{array}{c}\text { Panel A. Analysis of the Mean Across Countries } \\
\text { (Four Empirical Frictions, } \sigma=5.385)\end{array}$} \\
Mean & 0.731 & 0.790 & 0.190 & 0.161 & 0.299 & 0.140 & -0.059 \\
Proportions & 1.000 & 1.081 & 0.260 & 0.221 & 0.409 & 0.192 & -0.081 \\
Proportions & & 1.000 & 0.240 & 0.204 & 0.378 & 0.177 &
\end{tabular}

Panel B. Analysis of the Mean Across Countries

(No Penn Effect, $\sigma=9.142$ )

$\begin{array}{llllllll}\text { Mean } & 0.432 & 0.491 & 0.190 & 0.161 & \text { NA } & 0.140 & -0.060 \\ \text { Proportions } & 1.000 & 1.138 & 0.440 & 0.374 & \text { NA } & 0.324 & -0.138 \\ \text { Proportions } & & 1.000 & 0.386 & 0.329 & \text { NA } & 0.285 & \end{array}$

Panel C. Analysis of the Variance Across Countries

(Four Empirical Frictions, $\sigma=5.385$ )

$\begin{array}{llllllll}\text { Std. dev. } & 0.262 & 0.280 & 0.189 & 0.108 & 0.194 & 0.000 & 0.270 \\ \text { Proportions } & 1.000 & 0.539 & 0.186 & -0.174 & 0.527 & 0.000 & 0.461 \\ \text { Proportions } & & 1.000 & 0.511 & 0.032 & 0.457 & 0.000 & \\ & & & & & & & \\ \text { Corr }\left(\tau_{j}^{*}, \tau_{i j}\right) & 1.000 & 0.505 & 0.257 & -0.421 & 0.711 & 0.000 & 0.448\end{array}$

Panel D. Analysis of the Variance Across Countries

(No Penn Effect, $\sigma=9.142$ )

\begin{tabular}{llllllll} 
Std. dev. & 0.154 & 0.211 & 0.189 & 0.108 & NA & 0.000 & 0.260 \\
Proportions & 1.000 & 0.020 & 0.315 & -0.295 & NA & 0.000 & 0.980 \\
Proportions & & 1.000 & 0.769 & 0.231 & NA & 0.000 & \\
& & & & & & & \\
Corr $\left(\tau_{j}^{*}, \tau_{i j}\right)$ & 1.000 & 0.014 & 0.257 & -0.421 & NA & 0.000 & 0.583 \\
\hline \hline
\end{tabular}


Table 6. Decomposing Diffusion into Price and Income Effects Non-homothetic CES Preferences, Time Averaged Data 1928-1930

\begin{tabular}{ccc}
\hline \hline Relative & Price & Income \\
Diffusion & Effect & Effect \\
\hline
\end{tabular}

Panel A. Analysis of the Mean Across Countries

(Four Empirical Frictions, $\sigma=7.644, \epsilon_{N A}-\epsilon_{A}=1.579$ )

$\begin{array}{llll}\text { Mean } & 0.055 & 0.034 & 0.021 \\ \text { Proportions } & 1.000 & 0.619 & 0.381\end{array}$

Panel B. Analysis of the Mean Across Countries (No Penn Effect, $\sigma=7.307, \epsilon_{N A}-\epsilon_{A}=-0.777$ )

$\begin{array}{llll}\text { Mean } & 0.055 & 0.037 & 0.018 \\ \text { Proportions } & 1.000 & 0.677 & 0.323\end{array}$

Panel C. Analysis of the Variance Across Countries (Four Empirical Frictions, $\sigma=7.644, \epsilon_{N A}-\epsilon_{A}=1.579$ )
Std. Dev.
0.100
0.081
0.024
Proportions
1.000
0.802
0.198
Cross-country Corr.
1.000
0.988
0.842

Panel D. Analysis of the Variance Across Countries

(No Penn Effect, $\sigma=7.307, \epsilon_{N A}-\epsilon_{A}=-0.777$ )

$\begin{array}{llll}\text { Std. Dev. } & 0.100 & 0.085 & 0.020 \\ \text { Proportions } & 1.000 & 0.840 & 0.160 \\ \text { Cross-country Corr. } & 1.000 & 0.988 & 0.777\end{array}$




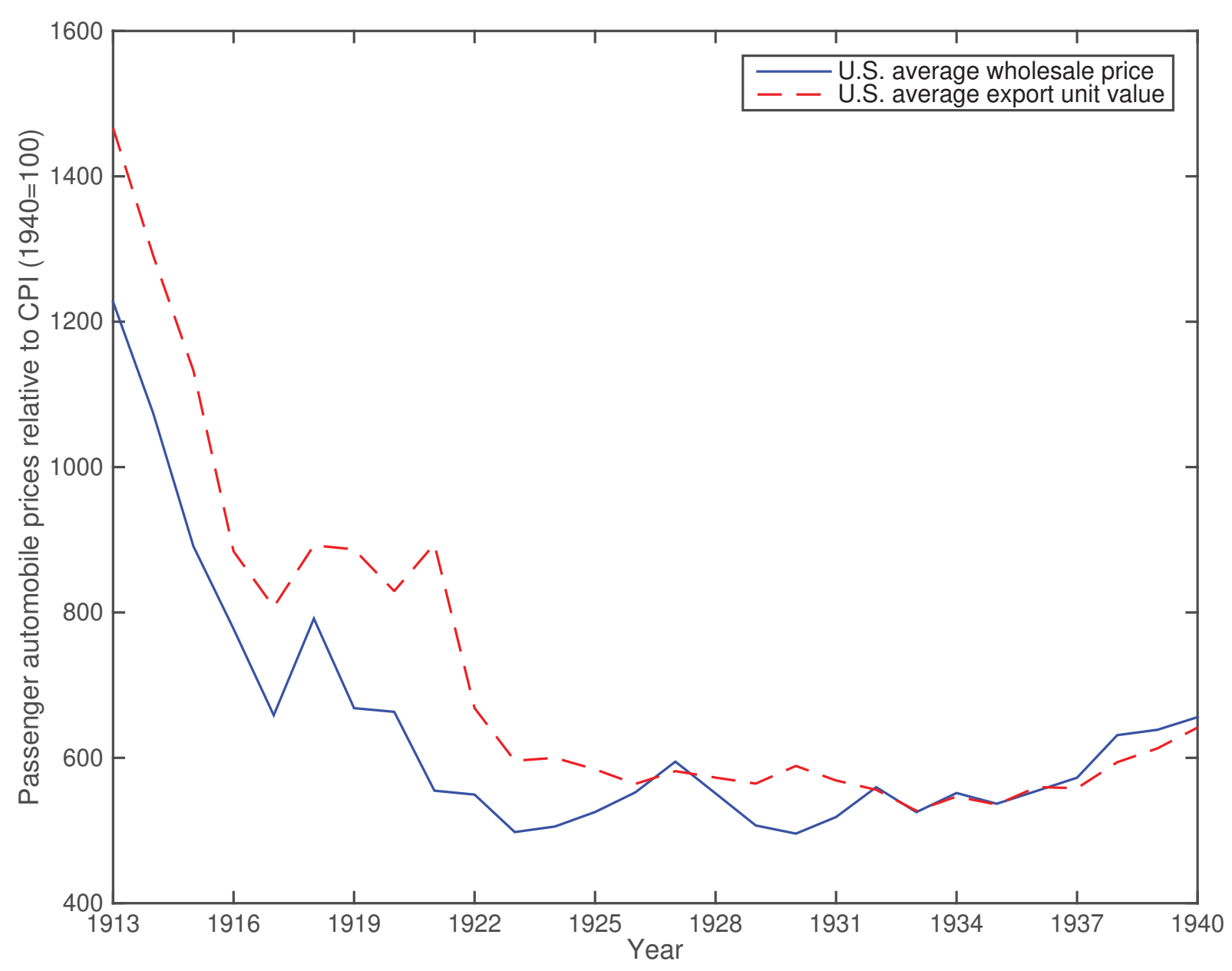

Figure 1. US Price and Export Unit Value (Value of sales divided by quantity sold). 


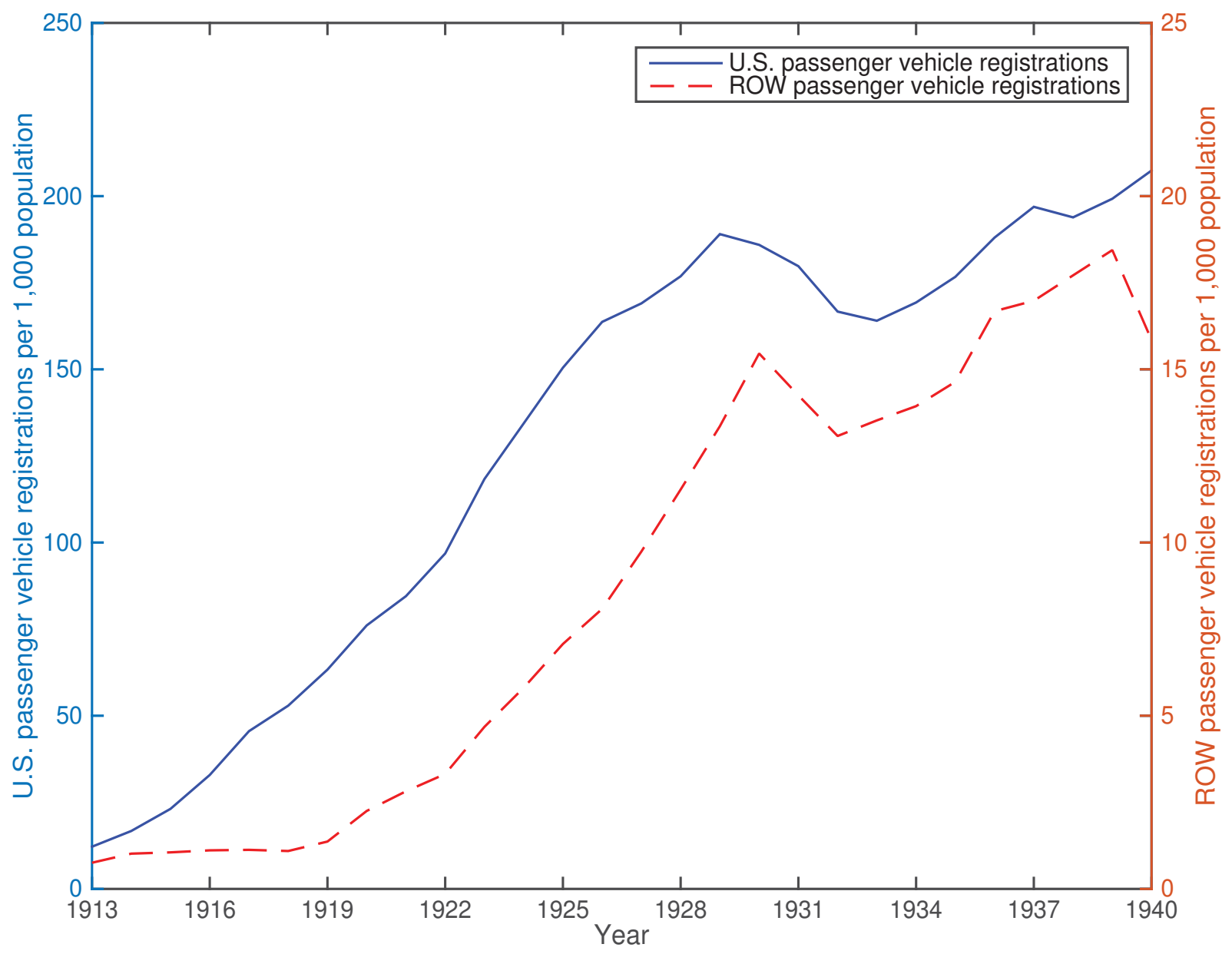

Figure 2. US and ROW Passenger Vehicle Registrations per 1000 Population. 


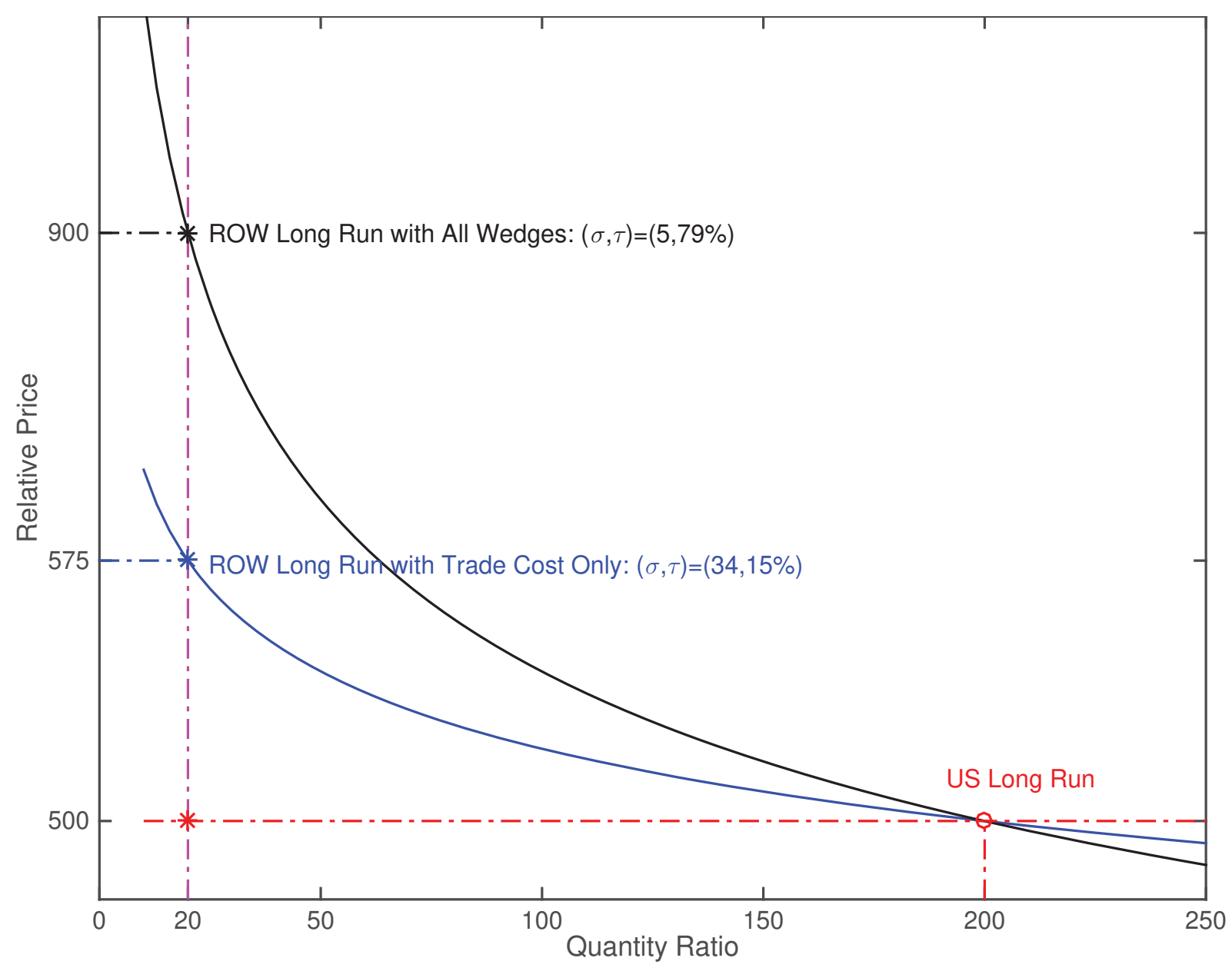

Figure 3. Identification Issues: Demand Elasticities and Trade Frictions. 

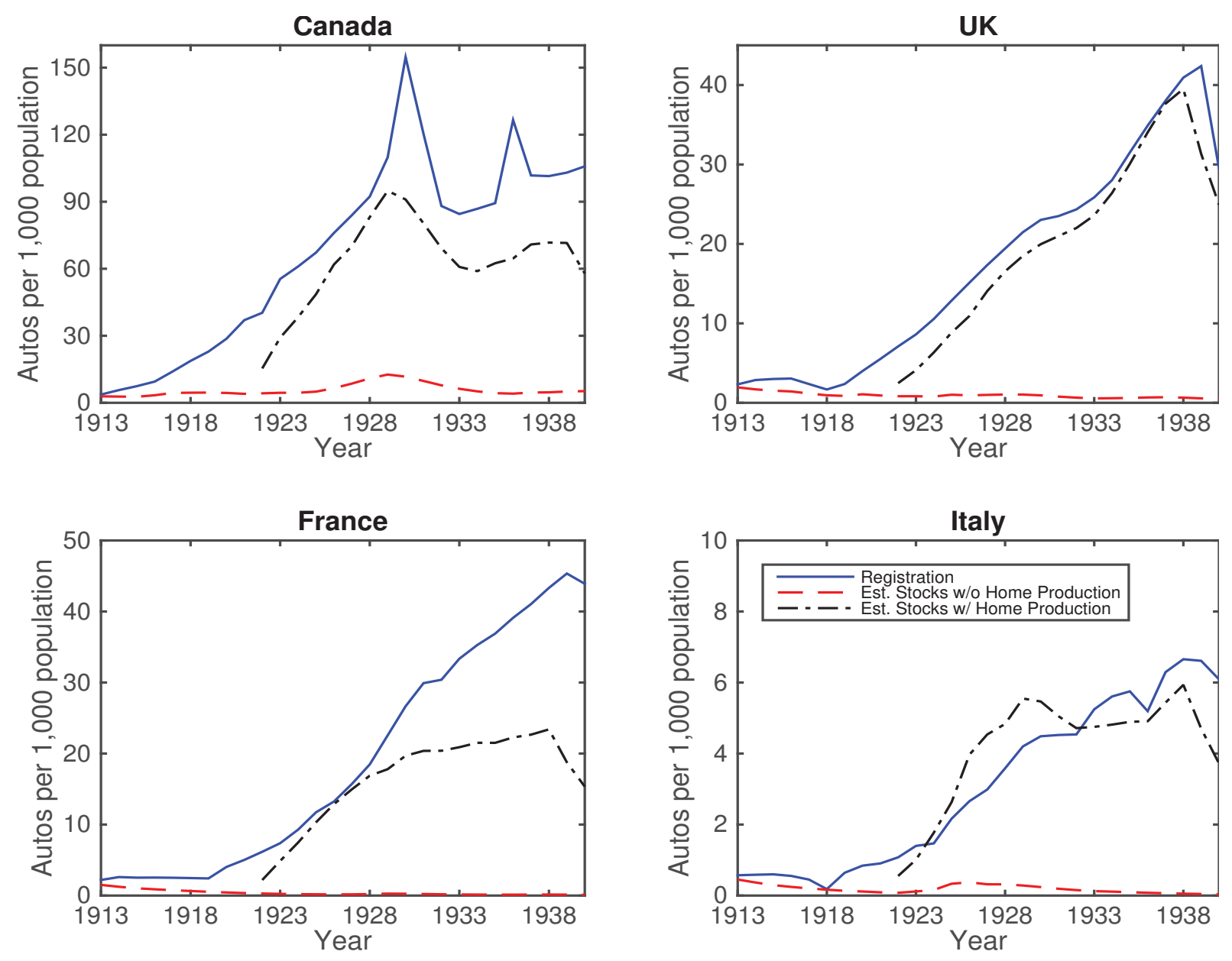

Figure 4. Registration and Stock-Flow Estimates (Automobile Producers). 


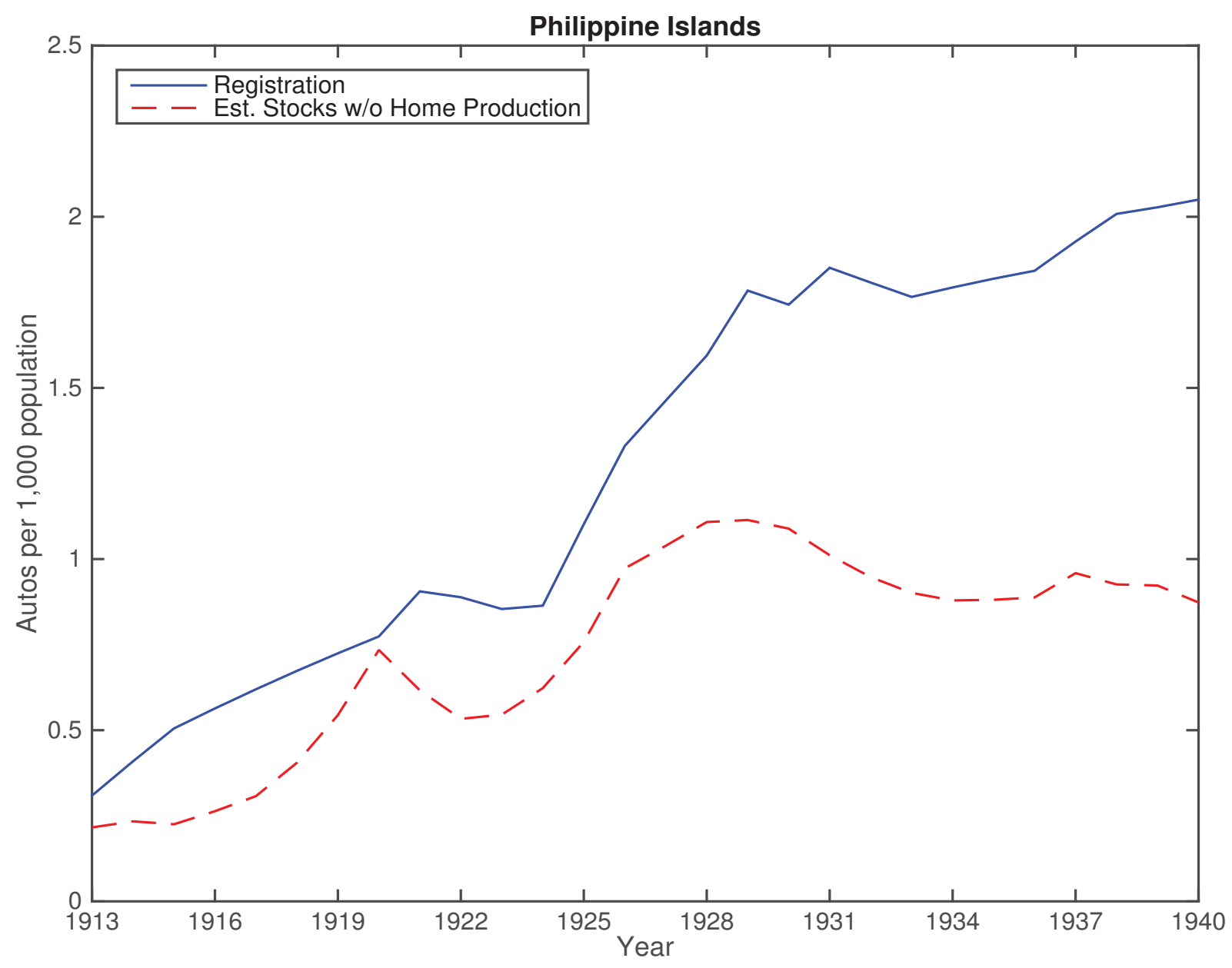

Figure 5. Registration and Stock-Flow Estimates (Automobile Non-producer). 


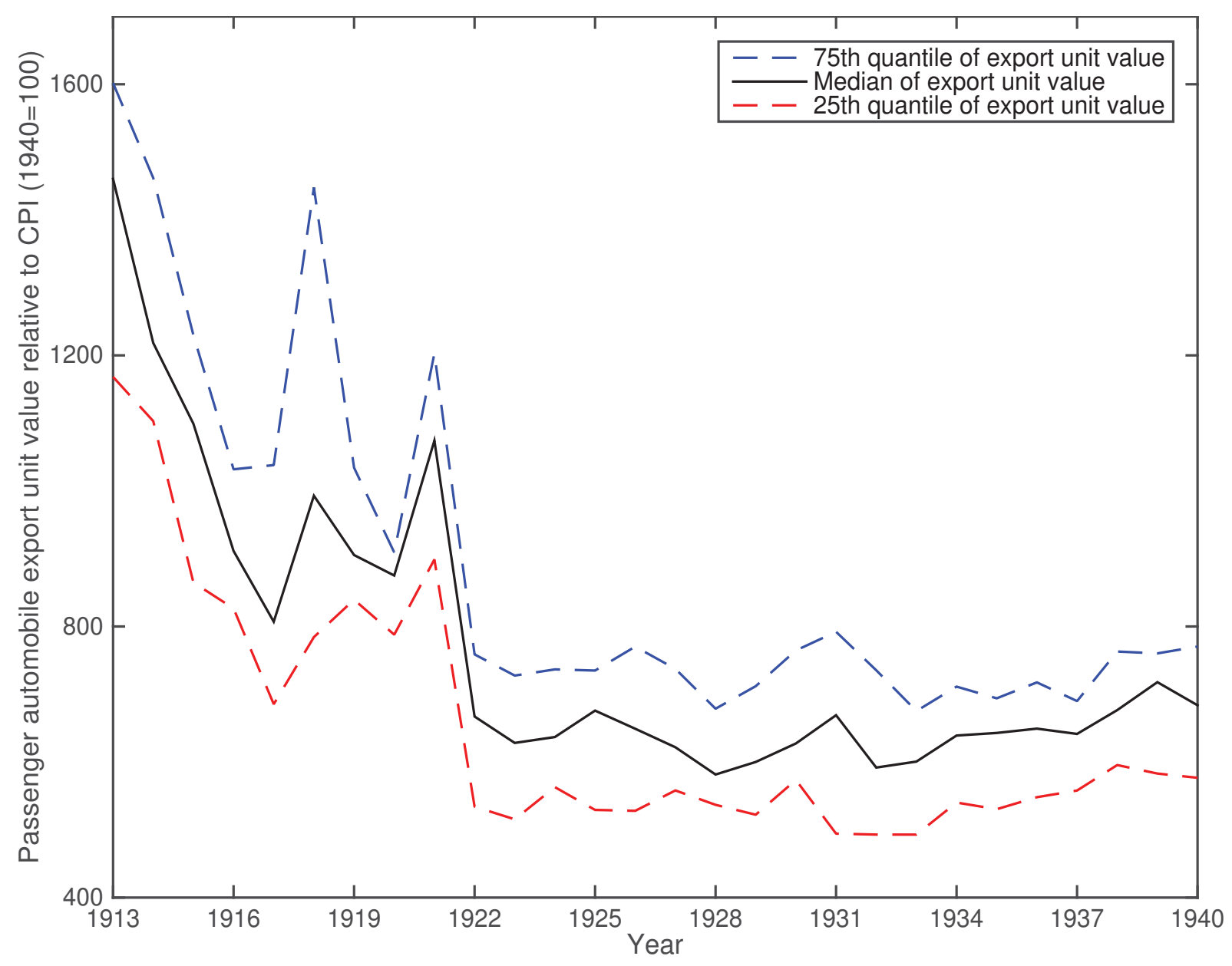

Figure 6. US Export Unit Values by Country. 